\title{
A COMPARATIVE ASSESSMENT OF THE EFFECTIVENESS OF HUMOROUS CONTENTS IN TELEVISION ADVERTISEMENTS: THE NIGERIAN CONTEXT.
}

\author{
E. Bankole Oladumiye ${ }^{1} \&$ Odji Ebenezer $^{2}$
}

\begin{abstract}
Humour has over time come to take its place in the Nigerian television advertising industry. Although a considerable volume of research has been conducted in the field of advertising humour in different parts of the world, however, little or no research on how humorous content can be effective across varying cultural contexts has been conducted. Adopting a slightly modified form of the Attention-Interest-Desire-Action model (AIDA) of measuring advertising effectiveness, a sample size of three hundred and ninety-eight (398) respondents was taken in Lagos, Nigeria with valid responses of three hundred and sixtytwo (362) participants. Following two hypotheses testing, the study showed a significant relationship between humour and interest or desire-arousal and recall effectiveness of television advertisements respectively. The study revealed that Humorous TV adverts are perceived to be more effective over non- humorous TV adverts with respect to attention, interest/desire and action for recall-induction and effective product communication with exception to message-clarity. The study revealed that humour, with respect to Nigerian culture versus other cultures, has similar significant effect on the effectiveness of television advertisement.
\end{abstract}

Keywords - Television-Advertisement, Humour, Communication, Culture, Assessment

\section{INTRODUCTION}

In the current increasingly competitive global market such as we have today, the need for effective advertising campaigns is of great importance. The Nigerian market has become increasingly flooded with varieties of similar products and services with consumers left with many attractive alternatives from which they may choose to satisfy their varying needs or wants. Consequently, this market situation has given rise to advertisers ${ }^{\text {ee }}$ need for improved marketing strategies, as well as the production of more effective, specific, target-oriented television advertisement with increasingly far greater reach, memorystimulating and attention/interest arresting qualities in an effective bid to brand their individual products or services as „The consumer"s ultimate choice"e in the minds of the target population. This vital advertising agenda has, over time engineered the interest of most advertisers in humour. In fact, it is estimated that between 30 and $42 \%$ of advertisements are intended to be humorous (Strick, Holland, Baaren, Knippenberg, and Dijksterhuis, 2013).

Although humour is used in various advertising media ranging from television, radio, internet, to print media, studies have however revealed that humour is more often used in television and radio than in any other media types (Hoyer, MacInnis and Pieters, 2013). This study, therefore, is on television advertisement as perceived by consumers in Lagos state, Nigeria.

According to Joanne and Pat (2009), recent content analysis of television adverts reveal that 15 to $20 \%$ of adverts contain humorous appeals. They further assert that advertisers think that adding humour to advertisements would have two beneficial effects: increased attention to the advert, as well as engineer favourable attitudes toward the product (Joanne and Pat, 2009). Although the broad question of humour's effectiveness in advertising is (seemingly) unanswerable, we can compile the accounts of humour research in the context of proper constraints to gain insights about its effects (Weinberger and Gulas, 1992). Therefore, in order to avoid generalizations about the effects of humour, to which this study has adopted a simple modified form of the AIDA model which measured the effect of humour using attention, communication/message-clarity, interest and desire, recall and action as parameters.

The rest of the paper is organized as follows. Hunour in advertising and summary of outcomes of previous researches are presented in section II. Research method and hypotheses are outlined in section III. Data collected, analysis and hypotheses testing are presented in section IV. Discussion and Concluding remarks are given in sections V and VI respectively.

\section{HUMOUR IN ADVERTISING AND SUMMARY OF OUTCOMES OF PREVIOUS RESEARCHES}

A. Humour in advertising -

Jean (2011) defined humour as lexicons, utterances and behaviours which can arouse pleasing, funny, exciting, whimsical and humorous feelings. The use of this advertising content type has become a common practice in advertising (Weinberger and

\footnotetext{
${ }^{1}$ Department of Industrial Design, Federal University of Technology, Akure, Ondo State, Nigeria.

${ }^{2}$ Department of Industrial Design, Federal University of Technology, Akure, Ondo State, Nigeria.
} 
Gulas, 1992). This widespread use of humour, according to Weinberger and Gulas (1992), coupled with the unresolved questions regarding it has drawn the attention of various communication researchers. However, little or none of these researchers worked on the Nigerian advertising scene which has become rather flooded with humour.

Humour in television advertising can be classified into the following, according to Li (2003): affectively humorous advertisements, cognitively humorous advertisements and socially humorous advertisements. All these advert-humour types are present in the Nigerian advertising contents.

\section{B. Humour, television advertisements and audience responses -}

Audience behaviour is the way the audience acts or reacts when television-adverts are being aired. This could be positive or negative depending on if, or not, it is in favour of the advertising objectives. Various studies conducted since 1962 till date, indicate that a substantial proportion of television programme audiences do not watch advertisements (Odji,and Oladumiye,2016). According to Odji, Oladumiye, Adelabu (2016), using several techniques, researchers have attempted to estimate the extent to which television audiences actually watch or avoid advertisements. Nuttall investigated this with „dayafter"e recall. Allen used time-lapse cameras to photograph the behaviour of television audiences in selected households. Steiner enlisted students as "observers" within selected households to observe the behaviour of other members. Wolfe, Brown, Thompson, and Greenberg used a combination of post-exposure interviews and in-home observers. Twyman used both diaries and telephone interviews which coincided with advert breaks. Bunn used the increase in electricity consumption during breaks to estimate the extent to which audiences did other things other than view television at these times. Collett developed a combination of video camera and recorder named "C-box". Brennan and Syn (2001) used time spent with "eyes on screen". All these studies agree in their findings that a substantial proportion of programme audiences do not watch advertisements. According to Odji, and Oladumiye (2016), the size of audience for advertisements shown on television is a matter of vital concern to advertisers. There is no use spending huge amounts of money, both to produce and air television adverts if no one is paying attention to them. This research, therefore, sets out to investigate the roles that humour plays, or can play in alleviating this negative consumer-attitude towards television advertisements with Lagos, Nigeria as a focal point, and compare the outcomes to the results of similar researches conducted in other cultures or environments.

\section{Some findings of prior humour- advertisement researches -}

Findings of prior investigations conducted on the effect of humour on the effectiveness of advertisements are hereby highlighted:

[1] Humour enhances the amount of attention given to adverts (Blanc, N., Brigaud, E., 2014; Weinberger and Gulas, 1992).

[2] Humour can enhance persuasion indirectly by increasing motivation to process adverts (Zhang \&Zinkhan, 2006) or by positively biasing adverts elaboration (Allen \& Madden, 1985).

[3] Humour directly increases positive attitudes towards adverts (Chung \& Zhao, 2003; Chattopadhyay \& Basu, 1990; Cline \& Kellaris, 1999; Gelb \& Zinkhan, 1986; Lee \& Mason, 1999).

[4] Humorous advertisements played between non-humorous programs would have better recall effects (Vanden Bergh, Lee, Quilliam, Hove, 2011).

[5] Humorous advertisements imparted better advertising effects than those without humorous elements (Wicks; Warren; Wicks, 2009).

[6] Humorous advertisements could enhance consumers" preferences for advertising sources. (Shen, Wang, Shen, 2009)

[7] Adopting humour in advertising can enhance consumers"e concerns and interest them (Yueh-Hua, 2014, Weinberger, Gulas, 1992)

[8] Humorous communication messages are more memorable and can also be shared more frequently than more serious messages [Campo, Askelson, Spies, Boxer, Scharp, Losch, 2013]. Humorous messages also maintain longer lasting memories of advertisements [Scott, Klein, Bryant, 1990].

However, contrary to the results presented above, some studies speculate that humour in advertising may lower message comprehension and also found humorous commercials are no more effective than comparable serious messages (Fang, 2011; Duncan, Nelson, Frontczak, 1984). All the above stated results were obtained from researches conducted in western environments/cultures. Therefore, this study, conducting its investigation strictly from the consumers ${ }^{\text {ee }}$ perspective in Lagos state, tested if humour is as effective as found in the above findings in terms of attention or attraction, interest/desire, recall and preferential behaviour with peculiarity to the Nigerian advertising recipients.

\section{RESEARCH METHOD AND HYPOTHESES}

\section{A. Research method -}

The study adopted the descriptive survey research method for the purpose of eliciting self-reports from the respondents. The opinions of respondents were sampled based on the respondents" favourite television advert and advertised product/service preferences in relation to attention, advertising-message-clarity, interest and desire, recall and action.

The sourced data include both primary and secondary data. Primary data was obtained through questionnaire. Secondary data include information obtained from the research work of other people, textbooks and journals. 
The target population for the purpose of this study is the consumers of certain advertised products and audiences of television advertisements within the adult age range living in Lagos state, Nigeria. The population sample was selected using simple random sampling. The sample size of three hundred and ninety-eight (398) respondents was considered for the study but only three hundred and sixty-two (362) responses could be used for the study. In order to extract information from the selected sample group, a questionnaire was constructed and adopted as a suitable instrument for data collection. Frequencies,

$x^{2}=\sum\left[\frac{\left(f_{o}-f_{e}\right)^{2}}{f_{e}}\right]$

percentages, mode and mean were used in analysing the collected data. With 3.0 as the computed mean, the decision rule was to accept any factor with a mean of 3.0 and above as positively perceived by the respondents and, hence accepted (A), while regarding any factor with a mean below 3.0 as negatively perceived and, therefore, rejected (R). Chi-square was the statistical tool adopted for the testing of the hypotheses. The decision rule was to reject $\mathrm{H} 0$ if significance level (p-value) is less than alpha $(\alpha=0.05$, the predetermined significance level). A dichotomous analysis procedure, as used by Odji 2016, in which responses were collapsed into two areas: agree and disagree, was adopted for the purpose of testing the hypotheses. As a modification, the "Undecided" was also considered not to be in favour of the Likert items. The Chi-square was obtained using:

Where $\mathrm{X} 2=$ Chi-square obtained, fo $=$ frequency obtained, fe $=$ frequency expected.

Mean was obtained using: $X=\Sigma \mathrm{f} / \mathrm{N}$

Where $\mathrm{X}=$ Mean, $\mathrm{x}=$ number of score, $\Sigma=$ summation, $\mathrm{N}=$ Number of Effective Questionnaires Collected

\section{B. Research hypotheses -}

The following hypotheses were put forward to guide this study:

Hypothesis 1:

H0: Humour has no significant effect on the interest/desire-arousing effectiveness of television advertisements.

H1: Humour has significant effect on the interest/desire-arousing effectiveness of television advertisements.

\section{Hypothesis 2:}

H0: Humour has no significant effect on the recall of television advertisements contents. 4

H1: Humour has significant effect on the recall of television advertisements contents.

These hypotheses were proposed on the premise that a television advert which is effective enough to arouse interest/desire and is as well memorable will often yield favourable consumer-behavioural preferences towards the advertised products and/or services.

\section{DATA PRESENTATION AND ANALYSIS}

398 questionnaires were distributed in Nigeria to randomly selected respondents. Brief discussions preceded the administering of the questionnaires for the purpose of acquainting the respondents with the purpose of the research (where needful, without influencing the respondentse opinions). Valid responses from 362 respondents were used for the purpose of testing the study hypotheses.

Humorous and non-humorous television advertisements were compared in terms of the following: Attention, Message clarity (communication), Interest and Desire and Action (consumption behaviour of the respondents). The results are presented in tables $1,2,3,4,5$ and 6 .

Data collected represents solely the responses and opinions of the respondents (based on their previous experiences and current consumption behaviour). The results obtained from sampling the Nigerian respondents were compared to the published results of researches conducted in the western, Arabian and Asian cultures. 
A Comparative Assessment of The Effectiveness of Humorous Contents in Television Advertisements:

The Nigerian Context.

Table 1: AIDA Assessment of humorous (against non-humorous) Television Advertisements in terms of attention

\begin{tabular}{|c|c|c|c|c|c|c|}
\hline Variable & Response & Frequency & Percentage & Mode & Mean & Remark \\
\hline ATTENTION & $\begin{array}{l}\text { Strongly Agree } \\
\text { Agree } \\
\text { Undecided } \\
\text { Disagree } \\
\text { Strongly } \\
\text { Disagree } \\
\text { Total }\end{array}$ & $\begin{array}{l}99 \\
67 \\
147 \\
35 \\
14 \\
362\end{array}$ & $\begin{array}{l}27.3 \\
18.5 \\
40.6 \\
9.7 \\
3.9 \\
100\end{array}$ & 3 & 3.6 & Accepted \\
\hline
\end{tabular}

Decision: Accept variable as positively perceived if mean is greater than the computed mean 3.0.

Humorous and non-humorous television advertisements were compared in terms of Attention. The result, as presented in table 1 shows that $27.9 \%$ of the respondents strongly agreed that humour in television advertisements arrests their attention towards their favourite advertisements, $18.5 \%$ agreed, $9.7 \%$ disagreed while only $3.9 \%$ strongly disagreed. However, the majority, representing $40.6 \%$ of the respondents, were undecided on the issue. While a total of $13.6 \%$ disagreed, a total of $45.8 \%$ agreed that humorous television advertisements arrest their attention much more than the non-humorous television advertisements. $40.6 \%$ of the respondents were undecided, casting doubts on the ability of humour in capturing audience attention may be questionable. However, with a mean of 3.6, humour is accepted as influential in arresting audiences ${ }^{\mathrm{ee}}$.

Table 2: AIDA Assessment of humorous (against non-humorous) Television Advertisements in terms of message clarity

\begin{tabular}{|l|l|l|l|l|l|l|}
\hline Variable & Response & Frequency & Percentage & Mode & Mean & Remark \\
\hline $\begin{array}{l}\text { MESSAGE } \\
\text { CLARITY }\end{array}$ & Strongly Agree Agree & 69 & 19.1 & 3 & 2.9 & Rejected \\
& Undecided & 46 & 12.7 & & \\
& Disagree & 122 & 33.7 & & \\
& Strongly & 36 & 9.9 & & \\
& Disagree & 89 & 24.6 & & \\
\\
\cline { 2 - 4 }
\end{tabular}

Decision: Reject variable as positively perceived if mean is less than the computed mean 3.0.

Humorous and non-humorous television advertisements were compared in terms of message-clarity. The result, as presented in table 2 , shows that $19.1 \%$ of the respondents strongly agreed that humour in television advertisements made the messages in their favourite television advertisements clearer, $12.7 \%$ agreed, $24.6 \%$ strongly disagreed while only $9.9 \%$ disagreed. However, the majority, representing $33.7 \%$ of the respondents, were undecided on the issue. While a total of $31.8 \%$ agreed, a total of $34.5 \%$ disagreed that humour in television advertisements make the advertising messages clearer. With $40.6 \%$ of the respondents were undecided, the ability of humour in capturing audiencese attention is doubtful. This is confirmed with a mean of 2.9 obtained which is 0.1 below the computed mean 3.0.

Table 3: AIDA Assessment of humorous (against non-humorous) Television Advertisements in terms of interest and desire

\begin{tabular}{|l|l|l|l|l|l|l|}
\hline Variable & Response & Frequency & Percentage & Mode & Mean & Remark \\
\hline INTEREST & Strongly Agree Agree & 109 & 30.1 & 1 & 3.3 & Accepted \\
/DESIRE/ & Undecided & 97 & 26.8 & & \\
EMOTION & Disagree & 26 & 7.2 & & \\
& Strongly & 37 & 10.2 & & \\
& Disagree & 93 & 25.7 & & \\
& Total & $\mathbf{3 6 2}$ & $\mathbf{1 0 0}$ & & & \\
\hline
\end{tabular}

Decision: Accept variable as positively perceived if mean is greater than the computed mean 3.0. 
Humorous and non-humorous television advertisements were compared in terms of interest/desire-arousal and sustenance. The result, as presented in table 3 , shows that $30.1 \%$ of the respondents strongly agreed that humour in their favourite television advertisements aroused their interest/desire for their favourite television advertisements (as well as in the product advertised), $26.8 \%$ agreed, $10.2 \%$ disagreed while $25.7 \%$ strongly disagreed. However, only a minority, representing $7.2 \%$ of the respondents, were undecided on the issue. Hence, while a total of $35.9 \%$ disagreed, a total of $56.9 \%$ agreed that humorous television advertisements aroused their interest and desire for their favourite television advertisements (as well as in the product advertised) more than the non-humorous television advertisements. Hence, with a mean of 3.3, humour is accepted as influential in arousing audiences ${ }^{\mathrm{ee}}$ interest and desire for their favourite television advertisements (as well as in the product or service advertised).

Table 4: AIDA Assessment of humorous (against non-humorous) Television Advertisements in terms of action

\begin{tabular}{|l|l|l|l|l|l|l|}
\hline Variable & Response & Frequency & Percentage & Mode & Mean & Remark \\
\hline ACTION & Strongly Agree Agree & 102 & 28.2 & 1 & 3.4 & Accepted \\
& Undecided & 92 & 25.4 & & \\
& Disagree & 97 & 26.8 & & \\
& Strongly & 03 & 0.8 & & \\
& Disagree & 68 & 18.8 & & \\
\\
\end{tabular}

Humorous and non-humorous television advertisements were also compared in terms of the favourable behavioural tendencies they arouse. The result, as presented in table 4 , show that $28.2 \%$ of the respondents strongly agreed that humorous television advertisements inspired in them favourable behavioural tendencies towards the advertised product, $25.4 \%$ agreed, only $0.8 \%$ disagreed while $18.8 \%$ strongly disagreed. $26.8 \%$ of the respondents were undecided on the issue. Hence, while a total of $19.6 \%$ disagreed, a total of $53.6 \%$ agreed that humorous television advertisements inspired in them favourable behavioural tendencies towards the advertised product more than non-humorous television advertisements. Hence, with a mean of 3.4, humour is accepted as being influential in arousing favourable behavioural tendencies towards advertised products and services.

Summarily, from Tables 1, 2, 3 and 4, respondents widely agreed, with all the obtained means greater than the computed mean 3.0, that humorous television advertisements were more effective than non-humorous television advertisements in terms of attention, arousal of interest/desire and preferential motivation with exception to message-clarity which was rejected at a mean 0.1 below the computed mean (3.0). Although, caution is expressed about the assumption of causation as several other factors, such as product relatedness or otherwise, type of humour mechanism, established brand recognition or brand loyalty and so on, might have influenced these outcomes.

The proposed hypotheses were tested using Chi-square.

\section{A. Hypotheses 1-}

$\mathrm{H}_{0}$ : Humour has no significant effect on the interest/desire-arousing effectiveness of television advertisements.

$\mathrm{H}_{1}$ : Humour has significant effect on the interest/desire-arousing effectiveness of television advertisements.

Consumers were made to rate non-humorous -advertisements against humorous television advertisements with interest and desire-arousing qualities as the criteria for comparison. The result is presented in table 5 . 
A Comparative Assessment of The Effectiveness of Humorous Contents in Television Advertisements:

The Nigerian Context.

Table 5: Relationship between humour and the interest-arousing effectiveness of television advertisements.

\begin{tabular}{|c|c|c|c|c|}
\hline \multicolumn{2}{|c|}{ Variable } & Observed N & Expected N & Residual \\
\hline \multicolumn{2}{|c|}{ Humorous Advertisements } & 206 & 181 & 25 \\
\hline \multicolumn{2}{|c|}{ Non-Humorous Advertisements } & 156 & 181 & -25 \\
\hline \multicolumn{2}{|c|}{ Total } & 362 & & \\
\hline $\mathbf{N}$ & DF & Chi-Square & Significant & Decision \\
\hline 362 & $\overline{1}$ & 6.9061 & 0.00859 & RejectH0 \\
\hline
\end{tabular}

Rejected at $p<0.01$

Since the $p$-value obtained is 0.00859 which is less than the predetermined significance level $(\alpha=0.05)$, the result is significant at $\mathrm{p}<0.01$. Therefore, we fail to accept the null hypothesis and, hence, the alternative hypothesis, which establishes a

significant relationship between humour and the interest/desire-arousing effectiveness of television advertisements, is thereby accepted. This agrees with the result computed in Table 1 as well as with the findings of prior foreign investigations (e.g.,

Weinberger and Gulas, 1992).

\section{B. Hypotheses 2-}

Ho: Humour has no significant effect on the recall of television advertisements contents.

$\mathrm{H}_{2}$ : Humour has significant effect on the recall of television advertisements contents.

Consumers were made to rate Non-humorous advertisements against humorous television advertisements with the consumers ${ }^{\mathrm{ec}}$ recall of the content of the television advertisements to which they have been exposed as the criteria for comparison. The result is as presented in table 6 .

Table 6: Relationship between humour and the consumerse recall of the content of the television advertisements to which they have been exposed.

\begin{tabular}{|l|l|l|l|}
\hline Variable & Observed N & Expected N & Residual \\
\hline Humorous Advertisements & 218 & 181 & 37 \\
Non-Humorous Advertisements & 144 & 181 & -37 \\
Total & $\mathbf{3 6 2}$ & & \\
\hline
\end{tabular}

\begin{tabular}{|l|l|l|l|l|}
\hline $\mathbf{N}$ & DF & Chi-Square & Significant & Decision \\
\hline 362 & 1 & 15.127 & 0.000101 & RejectH0 \\
\hline
\end{tabular}

Rejected at $p<0.01$

Since the p-value obtained is 0.000101 which is less than the predetermined significance level, the result is significant at $\mathrm{p}<0.01$. Therefore, we fail to accept the null hypothesis and, hence, the alternative hypothesis, which establishes a significant relationship between humour and the consumers" recall of the content of the television advertisements to which they have been exposed, is thereby accepted. This agrees with the findings of prior foreign investigations (Campo et al, 2013; Scott, Klein and Bryant, 1990; Vanden Bergh; Lee; Quilliam; Hove, 2011).

\section{DISCUSSION}

With a mean of 3.6, consumers in Lagos, Nigeria, agreed that humour enhances the level of attention they give to television adverts. The above stated results in table 1 agree with the outcomes of prior foreign researches that posit that humour enhances the amount of attention given to adverts. Weinberger and Spotts (1989) found that humorous advertising is more attractive than non-humorous advertising. Studies conducted by Weinberger and Gulas (1992) have shown that 94\% of advertising practitioners see humour as an effective way to gain attention. Furthermore, 55\% of advertising research executives believe humorous to be superior to non-humorous adverts in gaining attention (Madden and Weinberger, 1984). With a mean of 3.3, consumers in Lagos, Nigeria, agree that humour enhances their level of interest in, and desire for both the television adverts and the products/services they project. This positive effect in terms of attention and interest/desire, tells on the eventual favourable behavioural preferences of consumers in Lagos which is herein indicated with an accepted mean of 3.4. A similar research conducted in Islamabad by Qamar, Nouman, Muhammad Mahboob, Naveed (2015) revealed that humour in TV advertisement convinces the consumer"s attention, interest, desire and action to purchase products.

The objectives of this study were achieved as the findings show that humorous contents in TV advertisements affect the attention, interest/desire and recall; hence, the buying behaviour (actions) of consumers in Lagos state, Nigeria, which 
consequently establishes a similar effect of humour on TV-adverts in Nigeria even as it exists in some other parts of the world. It was established that television adverts which are effective enough to arouse interest/desire and are as well memorable will often yield favourable consumer behavioural preferences towards the advertised products and/or services in Nigeria.

However, with a mean of 2.9 which is only slightly below the computed mean of 3.0, the results obtained in this research indicate that humour does not necessarily improve message clarity in television adverts. This agrees with the findings of other investigators who posit that humour in advertising may even lower message clarity or comprehension (e.g. Fang, 2011; Duncan, Nelson, Frontczak, 1984).

\section{CONCLUSION}

Although a certain mystery remains as to how, when and why humour may or may not work (Spotts and Weinberger, 1997) and caution is also expressed about assumptions of causation, this study nonetheless revealed that humour has positive impact on advertising effectiveness in terms of interest and desire arousing, as well as in aiding recall of advert-contents in Lagos, Nigeria. Considering the findings of this study, it can also be concluded that humour in television advertisements has positive impact on the attention-arresting and buying behaviour of consumers and this effect cuts across environments. The study considers this effect to have stemmed from its influence on the attention of the consumers by augmenting audiences ${ }^{\text {ee }}$ arousal levels, and hence, influencing their behavioural preferences favourably. This often translates into wider advertising reach, improved sales of product and market shares, which are cogent reasons for being in business. The research Alternative Hypotheses $\mathrm{H} 1$ and $\mathrm{H} 2$ both have been accepted; hence, this study has revealed that the interest and investment in advertising humour in Nigeria is worthwhile but recommends a considerable blend of humour with other television-content-enhancement factors such as computer generated imagery and music.

\section{REFERENCES}

[1] Blanc, N., Brigaud, E. (2014).Humor in Print Health Advertisements: Enhanced Attention, Privileged Recognition and Persuasiveness of Preventive Messages. Journal of Health Communication. Vol. 29- Issue 7, P. 669-677. A. A. Reddy and B. N. Chatterji, "A new wavelet based logo-watermarking scheme," Pattern Recognition Letters, vol. 26, pp. 1019-1027, 2005.

[2] Campo, S., Askelson, N. M., Spies, E. L., Boxer, C., Scharp, K. M., \& Losch, M. E. (2013). "Wow, that was funny": The value of exposure and humor in fostering campaign message sharing. Social Marketing Quarterly, 19:84-96.

[3] Don, E. \& Nevan M. (1993).The Behaviour of Television Audiences During Commercial Breaks. Marketing Bulletin; 4, 12-18, Article 2. (Retrieved from http://marketing-bulletin.massey.ac.nz)

[4] Duncan, C.P., Nelson, J.E., Frontczak, N.T. (1984). The Effect of Humor on Advertising Comprehension.Advances in Consumer.11, $432-437$.

[5] Fang, Y. (2011).Humor and Brand Image-Shaping: A Content Analysis of America Runs on Dunkin" Campaign Television Advertisements. Ph.D diss., Liberty University.

[6] Gelb, B. D., \& Pickett, C. M. (1983). Attitude toward the ad: Links to humour and to advertising effectiveness. Journal of Advertising, 12, 34-42.

[7] Joanne C. and Pat V., (2009). The Effect of Humour on Recall of a Radio Advertisement. Journal of Broadcasting. Volume 24, Is sue 1, 1980, pages 1322. Published online 18 may 2009.

[8] Jean, S. (2011). Brand parody: A communication strategy to attack a competitor. J. Consum. Market.,28, 19-26.

[9] Li, PL. (2003).Humour classified ad system and form - on advertisement from 1997 to 2001 times award for flat lasses. London: Routledge; 2003

[10] Markiewicz, D. (1974). Effects of humor on persuasion. Sociometry, 37, 407-422. Retrieved from http://www.jstor.org/stable/2786391

[11] Strick, M., Holland R.,W.,B.vanBaaren, R., Knippenberg, A., Dijksterhuis, A. (2013).Humour in advertising: An associative processing model. European Review of Socioal Psychology, Vol. 24-Issue 1, p. 32-69.

[12] Qamar, F., Nouman, S., Muhammad,M. K., Naveed, A. (2015). Impact of comic factor in tv ads on buying behaviour of university students. International Letters of Social and Humanistic Sciences Online: 2015-03-10. Vol. 49, pp 12-20 www.scipress.com/ILSHS.49.12.

[13] Odji, E., Oladumiye, E.B., Adelabu,O.S. (2016). The Recall and Communicative Effectiveness of Computer Generated Imagery in Television Advertisements; A Case Study of Lagos, Nigeria.KEER 2016 International ConferenceonKansei Engineering and Emotion Research.University of Leeds, 31 August - 2 September 2016.

[14] Odji, E.,Oladumiye., E..B., (2016). Assessing Computer Generated Imagery on the Effectiveness Television Advertisement in Lag os State, Nigeria. An Unpubished thesis submitted to the department of Industrial Design, Federal University of Technology, Akure.

[15] Scott, C., Klein, D.M., Bryant, J.(1990).Consumer response to humor in advertising: A series of field studies Using Behavioral Observation. Journal of Consumer Research.16, 498-501.

[16] Shen, L., Wang, M.,Shen, R.(2009). Affective e-Learning: Using "Emotional” Data to Improve Learning in Pervasive Learning Environment. Educ. Technol. Soc. 2009, 12, 176-189.

[17] Spotts, H.E. \&Weinberger, M.G. (1997). Assessing the use and impact of humor on advertising effectiveness: A contingency approach. Amy L Parsons Journal of Advertising; 26, 3; ABI/INFORM Global pg. 17

[18] Umoh, S., H., \&Adeyemi, H., (1990). Causes of Divorce as Perceived by Students of Tertiary Institutions in Kwara State. Ilorin Journal of Education. Retrieved 02/01/2016 from www.unilorin.edu.ng

[19] Vanden Bergh, B.G.; Lee, M.; Quilliam, E.T.; Hove, T. (2011).The multidimensianl nature and brandimpact of user-generated ad parodies in social media.International Journal of Adverting, 30, 103-131.

[20] Hoyer, W.,D., MacInnis, D., J., Pieters, R. (2013). Consumer Behaviour.Sixth Edition.South-Western, Cengage Learning.

[21] Wicks, J.L.; Warren, R.; Fosu, I.; Wicks, R.H. Dual-Modality Disclaimers, Emotional Appeals, and Production Techniques in Food Advertising Airing During Programs Rated For Children.Journal of Advertising.2009, 38, 93-105.

[22] Weinberger, M.G, Gulas, C.S. (1992). The Impact of Humour in Advertising: A review. Journal of Advertising. 21, 35 -59.

[23] Weinberger MG, Spotts, H.E.(1989).Humor in US versus UK TV commercials: a comparison.Journal of Advertising.18, $39-44$.

[24] Weinberger, M.G. and Charles, S. G. (1992). The Impact of Humor in Advertising: A Review. Journal of Advertising, Volume XXI, Number 4 December 1992.

[25] Yueh-Hua L. (2014). How People Respond to Different Types of Humorous Advertising. British Journal of Economics, Management \& Trade, 4(9): 1419-1433. 